DIW BERLIN

Discussion

Papers
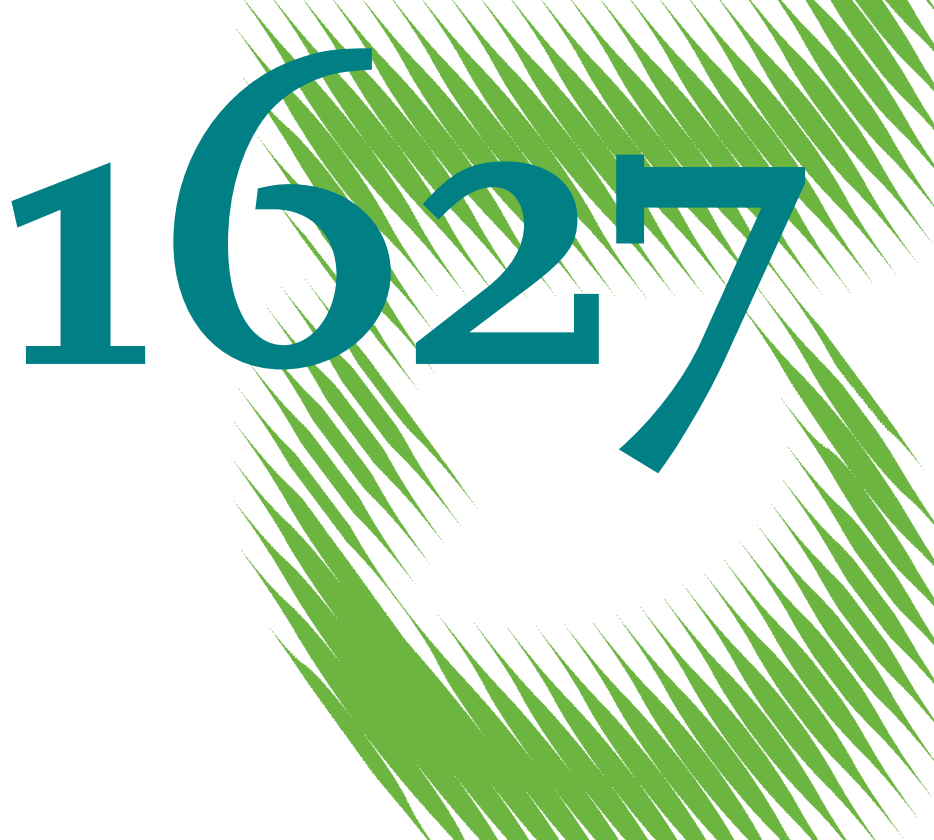

Who Bears the Burden of Social Security Contributions in Germany?

Evidence from 35 Years of Administrative Data 
Opinions expressed in this paper are those of the author(s) and do not necessarily reflect views of the institute.

IMPRESSUM

(C) DIW Berlin, 2016

DIW Berlin

German Institute for Economic Research

Mohrenstr. 58

10117 Berlin

Tel. +49 (30) $89789-0$

Fax +49 (30) $89789-200$

http://www.diw.de

ISSN electronic edition 1619-4535

Papers can be downloaded free of charge from the DIW Berlin website:

http://www.diw.de/discussionpapers

Discussion Papers of DIW Berlin are indexed in RePEc and SSRN:

http://ideas.repec.org/s/diw/diwwpp.html

http://www.ssrn.com/link/DIW-Berlin-German-Inst-Econ-Res.html 


\title{
Who bears the burden of social security contributions in Germany? Evidence from 35 years of administrative data
}

\author{
Kai-Uwe Müller ${ }^{\star}$, Michael Neumann ${ }^{\ddagger}$
}

December 8, 2016

\begin{abstract}
This paper provides evidence over a long time period on the question of who bears the burden of social security contributions (SSC) in Germany. Following Alvaredo et al. (2016) we exploit kinks in the budget set generated by a drop in the marginal SSC rate at earnings caps. Based on cross-sectional earnings distributions the framework does not rely on policy reforms. Applying the approach to administrative data for West Germany facilitates a comprehensive incidence analysis between 1975 and 2010. We find that neither employers nor employees shift a substantial part of their SSC burden. These results are consistent over the whole time period and in robustness checks corroborating previous findings. A small trend towards a slight increase in the SSC burden falling on employees is not statistically significant.
\end{abstract}

Keywords: incidence; social security contributions; discontinuities

JEL classification: H22; J38; H55

* Corresponding author, German Institute for Economic Research Berlin (DIW), Mohrenstr. 58, D-10117 Berlin, Tel.: +49 3089789 154, Fax: +49 3089789 114, E-mail: kmueller@diw.de

$\ddagger$ German Institute for Economic Research Berlin (DIW), Mohrenstr. 58, D-10117 Berlin, Tel.:

+49 3089789 353, Fax: +49 3089789 114, E-mail: mneumann@diw.de

We would like to thank Peter Haan who read and commented on an earlier draft of this paper. We are also indepted to Stuart Adam, Leon Bettendorf, Nicole Bosch, Antoine Bozio, Thomas Breda, Julien Grenet, Luke Haywood, and Barra Roantree for helpful comments and discussions. This research has been conducted within the project "The Impact of Social Security Contributions on Earnings: Evidence from administrative data in France, Germany, the Netherlands and the UK" (HA 5526/3-1 (ORA)) funded by the German Research Foundation (Deutsche Forschungsgemeinschaft, DFG). 


\section{Introduction}

Social security contributions (SSC) account for a large part of total taxation in Germany amounting to about $14 \%$ of GDP. They are formally borne in virtually equal shares by employers and employees. The total revenue generated by SSC exceeds that of personal income taxation. Their contribution to government funding in Germany is one of the highest among industrialized countries (OECD, 2016). It is thus from a fiscal, but likewise from a distributional perspective an important question who is actually bearing the economic burden of SSC.

The overall empirical evidence on economic incidence of SSC is mixed (Melguizo and Gonzalez-Paramo, 2013). Institutional variation in wage setting mechanisms, e.g. the centralization of the bargaining process (Alesina and Perotti, 1997; Daveri and Tabellini, 2000), may explain part of this variation. Several recent studies challenge the conventional view that incidence is with employees as demand are substantially larger than supply elasticities (Saez et al., 2012 and the other papers in this issue). Similarly, current studies with German data based on an SSC reform (Neumann, 2015) as well as the discontinuity approach followed here (Müller and Neumann, 2016) also find that statutory and economic incidence coincide. Previous studies for Germany are, however, limited to a unique reform of earnings caps in 2001 or rely only on few selected years of data since the middle of the 1990s

Based on administrative data for West Germany from 1975 to 2010 we are in this paper able to investigate SSC incidence over a long-term horizon. First, we ask whether a consistent longitudinal pattern of estimates emerges. Second, we investigate (a) shift(s) in economic incidence over time. Do previous results reflect recent developments in wage negotiations or has economic incidence remained stable since the mid-1970s? Third, we relate this longitudinal pattern of findings to factors that potentially determine the burden sharing of SSC. Besides cross-national differences, there is, e.g., also longitudinal within-country variation in institutional settings. The continuous decline in collective bargaining coverage in Germany since 1975 may, among other things, have influenced economic incidence.

In accordance to the other studies in this issue we follow the framework proposed by Alvaredo et al. (2016). Their approach exploits the fact that in a given SSC schedule the marginal SSC rate drops discontinuously at an earnings cap. The 
drop generates a downward kink in the average tax schedule. When employees (employers) bear (part of) the SSC burden of their counterparts, a negative (positive) discontinuity emerges in the distribution of gross earnings at the cap. The gross earnings distribution is smooth around the cap only when statutory and economic incidence coincide. The estimated sign and size of the discontinuity in the earnings distribution are thus informative about economic incidence.

Our study utilizes the Sample of Integrated Labor Market Biographies (SIAB), an administrative data set that provides individual earnings information on a daily basis. It is very easy to construct cross-sectional earnings distributions per year. For West Germany it covers the period from 1975 up to 2010. The SIAB is characterized by its precise gross earnings measure and sufficient sample size. Both are prerequisites for identifying discontinuities in earnings distributions (vom Berge et al., 2013b,a). The framework developed by Alvaredo et al. (2016) is based on crosssectional data and does neither rely on policy reforms nor longitudinal information. It is thus applying the discontinuity approach to the SIAB data that allows us to consistently analyze the yearly earnings distributions for West Germany over such a long period of time. Estimates for East Germany based on more recent waves are provided as robustness check. The earnings measure of the SIAB is, however, censored at the earnings cap of pension and unemployment. We therefore have to restrict the analysis to the earnings cap of health and long-term care insurance which is located below.

We do not find statistically significant discontinuities around the caps of most gross earnings distributions analyzed. Estimates are consistent over a long time horizon and prove to be robust in several sensitivity checks. This implies that neither employers nor employees shift a significant part of their SSC burden corroborating recent evidence for a number of countries. If at all there is a slight trend over time towards a higher SSC burden for employees. This would be consistent with the erosion of centralized wage setting institutions in Germany. The difference in estimates over time is very limited in magnitude, however. We therefore conclude that economic and statutory coincide over the complete period of analysis.

The rest of the paper is in four parts. Section 2 informs about the German institutional setting. The data set and estimation approach are briefly introduced in section 3. Section 4 presents our empirical results and section 5 concludes. 


\section{Institutions}

Health and long-term care insurance are two pillars of the German social security system. We are not able to analyze pension and unemployment insurance which are the other two branches because our data is censored a their earnings cap. The flat contribution rates are based on daily gross earnings. For most of the period 1975 to 2010, SSC had formally been shared equally between employees and employers. Since 2004 a share of 0.9 pp. has to be paid solely by employees which increases by $0.25 \mathrm{pp}$. for employees without children. The total SSC rate increased from roughly 30\% to more than $40 \%$ between 1975 and 1995 (Fig. 1). The main drivers for this gradual increase were the SSC rates of health and unemployment insurance. Since then SSC rates have been quite constant with pension (around 20\%) and health insurance (around 14\%) as the most important branches.

Fig. 1: Development of SSC rates and caps over time

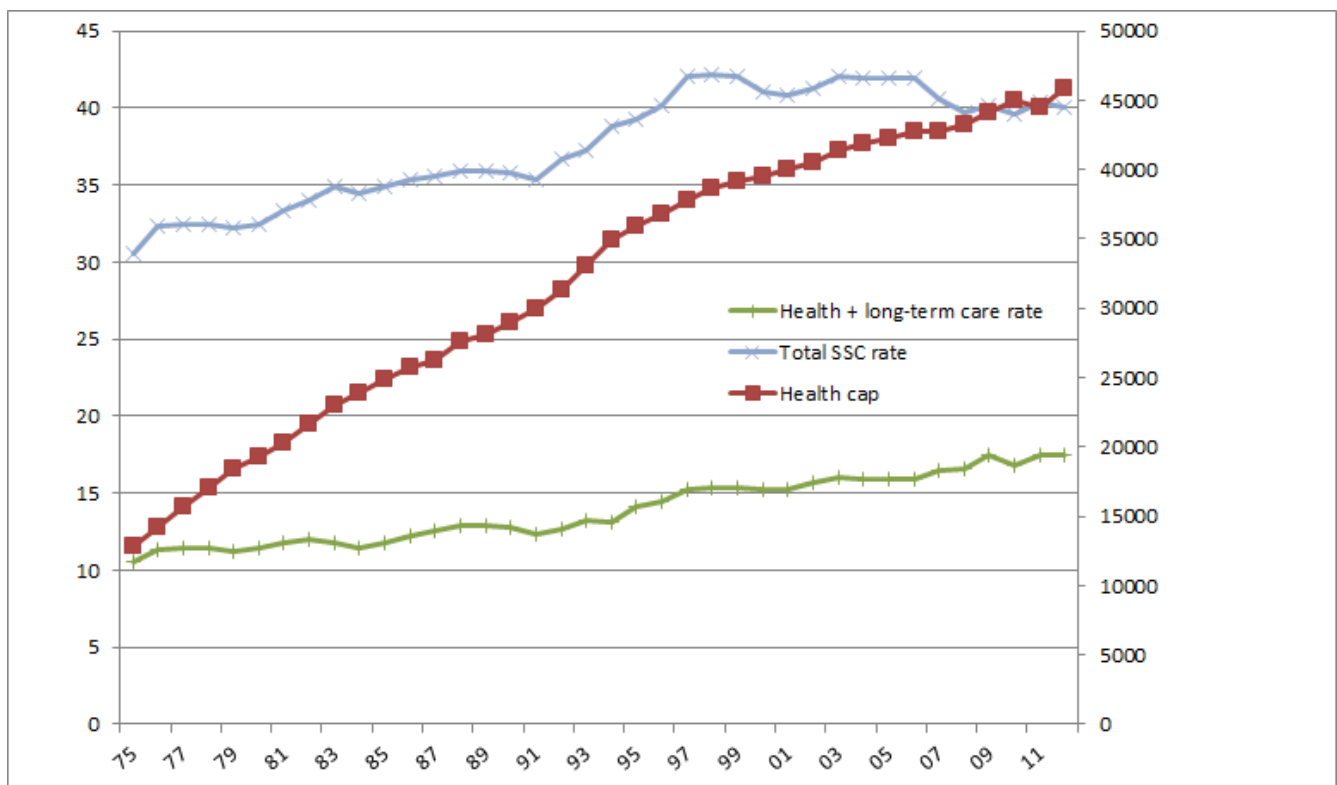

Notes: The horizontal axis represents years. The left vertical axis is in percent and pertains to the rates. The right vertical axis is in yearly earnings and pertains to the cap. The additional fee for childless employees since 2005 is omitted. The change of SSCs becoming effective in July 2005 are considered as of 2006. SSC rates for health insurance have varied between health insurance companies until 2006; the numbers are averages (Grabka, 2004).

Source: German Statistical Office; own calculations.

Marginal SSC rates only apply up to earnings caps. There is one threshold for pension and unemployment insurance, another one for health and long-term care insurance. Both caps differed between East and West Germany until 2001 when the 
health insurance cap in East Germany was adjusted to the level of West Germany. Due to data limitations (section 3) we restrict the analysis to the West German earnings cap of health and long-term care insurance. At that cap the drop in the marginal SSC rate is the sum of the contribution rates of those two schemes. In the remainder of the paper we only refer to both as "health care insurance".

The drop in the marginal SSC rate at the health cap is subject to yearly gradual changes. It has risen steadily from approximately $10 \%$ in 1975 to $17.45 \%$ in 2012 (Fig. 1). Under constant economic incidence potential discontinuities should thus have increased in size over time. The nominal location of the health cap also varies over the observation period. Caps are adjusted according to the change in the average gross wage bill in the preceding year. There are no discontinuous changes during our observation period (Fig. 1). This means that the reduction in the SSC contributions generated by the drop in the marginal rate at the cap becomes larger in absolute terms which could affect salience.

The linkage between contributions and benefits is negligible for health insurance. One peculiarity of the German social security system might affect our empirical analysis. Employees with earnings exceeding the income threshold for compulsory insurance (called Versicherungspflichtgrenze), are eligible to substitute public for private health insurance. This threshold coincided with the earnings cap of health insurance until 2003 when the former was increased. We neither observe an individual's insurance status nor the cost of private insurance. Thus, the change in the average SSC rate of an unknown fraction of our sample at the earnings cap remains unclear. Yet, there are two reasons why sizeable distortions can be ruled out. First, the effect of the earnings cap for employers' SSC are similar under public and private insurance. Second, most employees located slightly above the cap are still publicly insured. (Müller and Neumann, 2016)

In this paper we investigate SSC incidence over a relatively long period of time. Potential changes could be driven by shifts in the relative bargaining power of employers and employees. One indicator for the bargaining position is an employee's coverage by collective bargaining agreements (CBA). Between 1970 and 2010 coverage has decreased from almost $80 \%$ to slightly more than $60 \%$ in West Germany (Fig. 2).

It is even lower with about $50 \%$ in East Germany. Unfortunately we cannot 
Fig. 2: Employees' coverage by collective bargaining agreements (in percent)

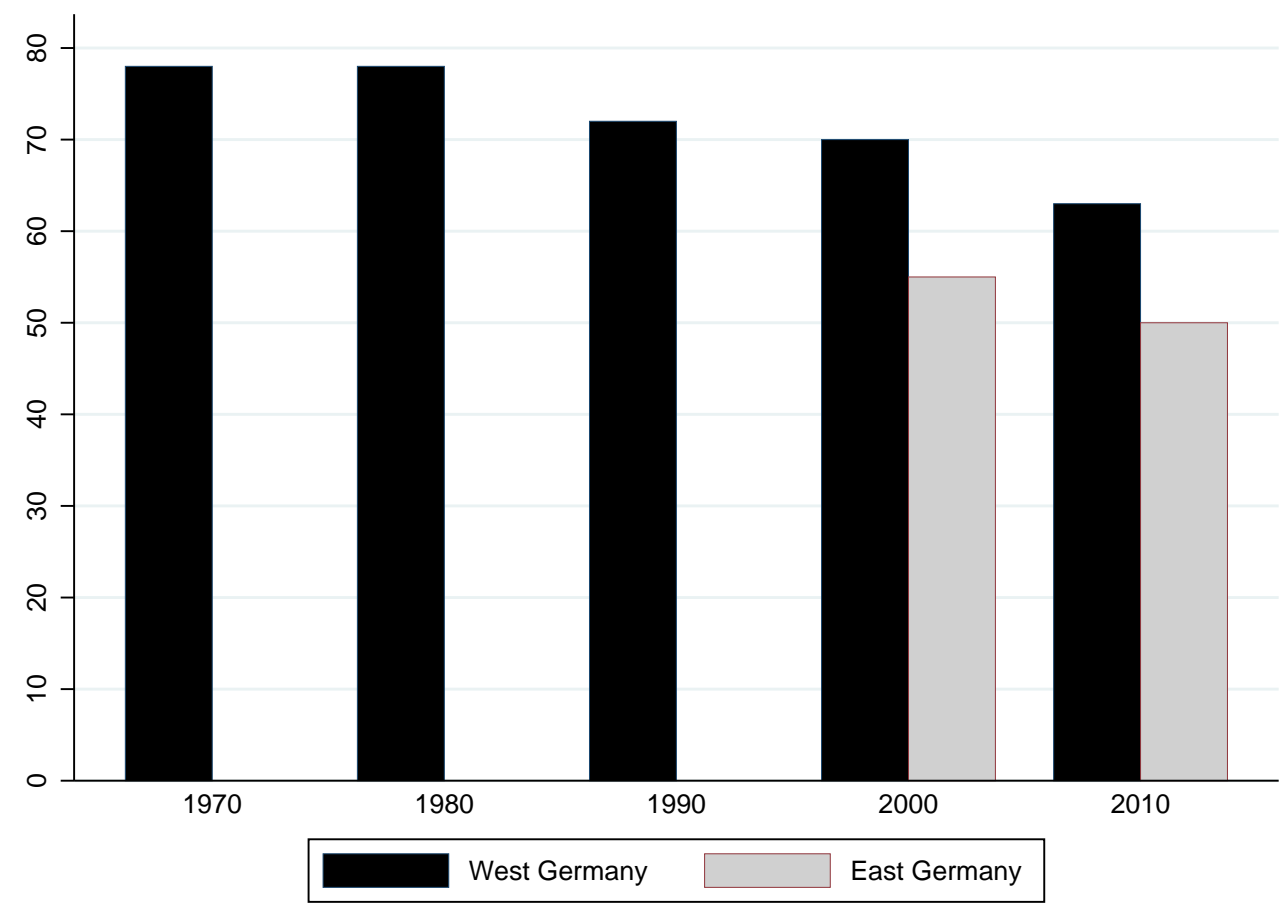

Notes: Coverage means that the establishment or firm is either directly under an agreement or complies with the collectively bargained wages.

Source: ICTWSS: Database on Institutional Characteristics of Trade Unions, Wage Setting, State Intervention and Social Pacts in 51 countries between 1960 and 2014 (figures for 1970 to 1990, see http://www.uva-aias.net/208); German Establishment Panel (figures for 2000 to 2010, see Fischer et al., 2008, 2009).

exploit this regional variation consistently due to data limitations (section 3). CBA coverage is also correlated with the degree of centralization in wage bargaining which has shown to affect economic incidence (Melguizo and Gonzalez-Paramo, 2013).

Other indicators like union coverage or union membership also point to a weakening of employees bargaining position over time (Fitzenberger et al., 2013). Besides the evolution of bargaining institutions there are a number of other factors that may also affect the sharing of the SSC burden among employers and employees. Incidence might, e.g., vary over the business cycle. Similarly, long-term trends in the evolution of wages and employment will influence the leeway of employers and leverage of employees in wage negotiations. 


\section{Data and Estimation}

\section{Administrative data}

The empirical analysis is based on the Sample of Integrated Labour Market Biographies (SIAB). The SIAB data set $^{1}$ is a representative two percent sample of all individuals for whom an employer's report to the social security system exist. Three features make this data set particularly suitable for our analysis. First, the earnings information is very accurate because it is generated during administrative processes and includes all sorts of payments from the employer subject to SSC. A precise earnings measure is essential because the cross-sectional approach followed here is quite sensitive to measurement error (Müller and Neumann, 2016). Second, the sample size is considerably larger than in survey data sets which facilitates a distributional analysis (Fig. 3 below). Third, for West Germany the data goes back to 1975 which allows for analyzing economic incidence on a yearly basis over a long period of time.

A major drawback of the SIAB data is that gross earnings are capped at the earnings cap of pension insurance. The analysis is thus restricted to the earnings cap of health insurance which is located below the pension/unemployment insurance cap. Moreover, civil servants and the self-employed are not included as they do not contribute to the general SSC scheme.

We do not consider incidence for East Germany in the main analysis: First, for East Germany the data does not cover the years before the reunification in 1990. In the subsequent years the newly introduced system was far from stable with doubledigit yearly percentage increases of the earnings cap until 1995. Second, the sample size is much smaller. The increase around the health cap to the West German level in 2001 further reduced the amount of uncensored observations above the health cap. We discuss pooled estimates as robustness check for later years.

The sample is further restricted to full-time employees between 17 and 65 years. This is not very restrictive, however, as the earnings cap is rather high up in the distribution (Fig. 3). We also drop apprentices as well as home workers. More-

\footnotetext{
${ }^{1}$ The German name is Stichprobe der Integrierten Arbeitsmarktbiografien. See Dorner et al. (2011) for a detailed description of the data.
} 
over, the sample is restricted to one employment spell per individual and year by excluding spells not covering June 30th. In the case of parallel employment spells the employment spell with highest earnings is kept. The final sample size per year varies between 300 and 350 thousand observations (Fig. 3).

Fig. 3: Yearly sample size and location of health cap over time

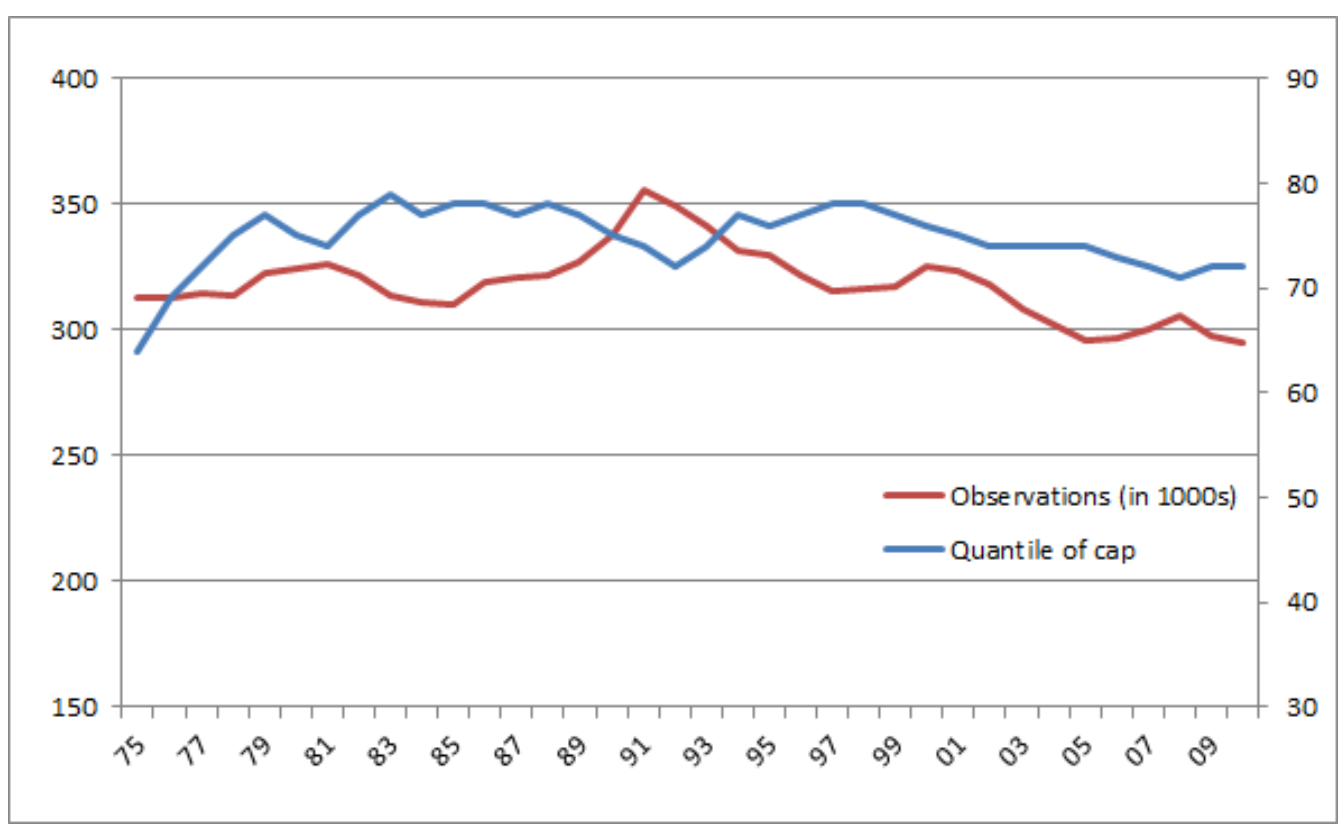

Notes: The left vertical axis pertains to the sample size and depicts observations in 1000s. The right vertical axis is in percent and pertains to the fraction on employees with earnings below the cap.

Source: SIAB; own calculations.

\section{Estimation}

In accordance to the other studies in this issue we estimate economic incidence by applying a cross-sectional framework (Alvaredo et al., 2016). The marginal SSC rate drops discontinuously at earnings caps of SSC. This generates a downward kink in the average tax schedule. It can be shown that when employers (employees) are able to shift some of their SSC burden to the respective other side of the labor market, a negative (positive) discontinuity emerges in the distribution of gross earnings at the cap. If the complete burden is shifted to one side, the discontinuity is proportional to the drop in the marginal SSC rate. The gross earnings distribution remains smooth around the cap when statutory equals economic incidence.

The empirical challenge is to identify the size of a potential discontinuity at the cap of a given earnings distribution. We apply two estimation strategies which 
both have been shown to work well (Müller and Neumann, 2016). First, the nonparametric sorting test proposed by McCrary (2008) estimates the density to the left and right of the cap by local linear regressions. In the second approach we fit a polynomial of degree nine to the density values at the center of each histogram bin. The discontinuity is measured by an indicator variable differentiating between bins above and below the cap. In the basic specification we use 200 bins on either side of the cap. The bin size is chosen such that the first bin to the left of the cap contains 400 observations per year. We test the robustness of our results with respect to these choices.

\section{Empirical results}

This section presents the estimation results for gross earnings distributions in West Germany between 1975 and 2010. We apply the non-parametric and the parametric estimators. The question is whether a significant discontinuity emerges around the earnings cap of health insurance. In particular we examine how the discontinuity estimates evolve over time and whether we can infer a substantial shift in incidence from this pattern. A set of robustness checks complements the main analysis.

\section{Main analysis}

We, first, estimate discontinuities separately for gross earnings distributions in each single year. Point estimates vary considerably, both for the non-parametric and the parametric approach (Fig. 4). Given the limited size of the yearly samples, this does not come as a surprise. The methodology applied is demanding in terms of the sample size which is reflected in the large and often overlapping confidence intervals. Single point estimates should thus not be over-interpreted.

The overall pattern of estimates is nevertheless insightful: The point estimates vary consistently and rather randomly around zero within an interval of approximately 0.05 and -0.05 (Fig. 4). The 95\%-confidence interval of most estimates includes zero which would imply that economic and statutory incidence coincide. Linear regression lines fitted to the yearly point estimates show a slightly negative slope. This suggests that the relative burden of SSC borne by employees increased 
Fig. 4: Point estimates of discontinuity, all years separately
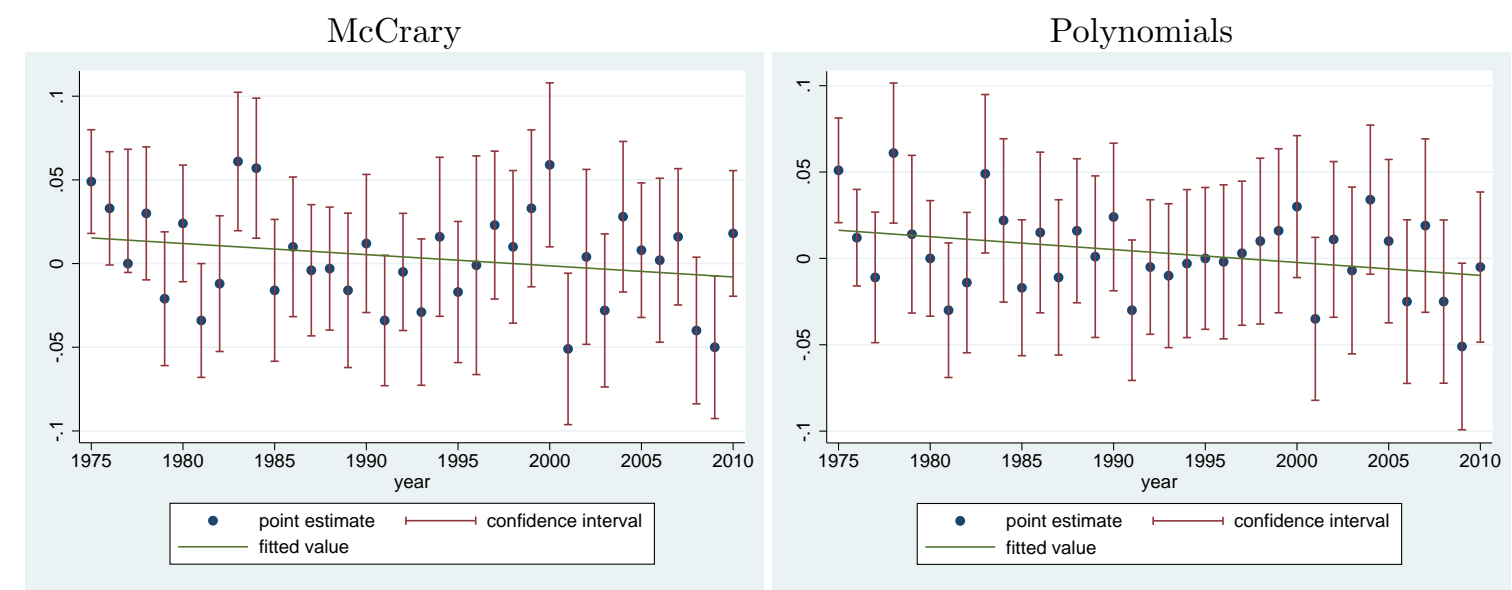

Source: SIAB; own calculations.

slightly over time. The magnitude of this change over time is very limited, however, and most confidence intervals overlap. None of the fitted values suggests that either employees or employers have been able to shift a substantial part of their burden to the respective other side of the market since 1975.

In order to reduce the fluctuation in point estimates and increase precision we repeat the analysis on data pooled by periods of five years. We find very small and mostly statistically insignificant discontinuities at the earnings cap (Tab. 1).

Tab. 1: Discontinuity estimates - five year periods

\begin{tabular}{lcrrrrr}
\hline \multirow{2}{*}{ Period } & \multicolumn{5}{c}{ McCrary } & \multicolumn{3}{c}{ Polynomials } \\
& & \multicolumn{1}{c}{ p.e. } & \multicolumn{1}{c}{$\mathrm{t}$} & \multicolumn{1}{c}{ p.e. } & \multicolumn{1}{c}{$\mathrm{t}$} & $\mathrm{N}$ \\
\hline $1975-79$ & -.112 & .026 & 3.00 & .020 & 2.65 & 848 \\
$1980-84$ & -.117 & .016 & 1.69 & .003 & .30 & 883 \\
$1985-89$ & -.125 & -.006 & -.51 & .004 & .45 & 821 \\
$1990-94$ & -.129 & -.015 & -1.45 & -.003 & -.34 & 844 \\
$1995-99$ & -.149 & .008 & .73 & .000 & .00 & 820 \\
$2000-04$ & -.156 & -.001 & -.09 & .006 & .58 & 786 \\
$2005-10$ & -.165 & -.012 & -1.23 & -.014 & -1.46 & 865 \\
\hline
\end{tabular}

Notes: $\Delta t$ - average drop in marginal SSC rate, p.e. - point estimate, $\mathrm{t}-\mathrm{t}$-value, $\mathrm{N}$ - observations in 1000s $(\alpha=0.05)$.

Source: SIAB; own calculations.

We get the smallest and largest point estimates for the non-parametric approach amounting to -.015 for $1990-94$ and .026 for $1975-79$. To put their magnitude in perspective, let us recapitulate the relation between economic incidence and the implied discontinuities: should employers (employees) be able to shift their total SSC 
burden, a negative (positive) discontinuity would result in size of the drop in the marginal tax rate. The magnitude of all estimated positive and negative discontinuities is in absolute values markedly smaller than the tax changes which are also displayed in Tab. 1. This lends support to the interpretation that economic and statutory incidence coincide over the whole period under observation. Put differently, employees and employers share the burden of SSC roughly equally. Looking at the positive estimates in the first two and the negative estimates in the last period there is a slight trend over time towards a somewhat higher burden for employees. This would be consistent with a decline of their bargaining power in wage negotiations. Similar to the estimates for single years we do not want to overstate this pattern, though.

\section{Robustness}

The discontinuity estimates are subject to several choices regarding the empirical specification. We therefore run a number of sensitivity tests which are restricted to the estimates based on pooled data. In the baseline specification the period-specific bin size is chosen such that 400 observations per year are included in the first bin to the left of the earnings cap. The estimation interval consists of 200 bins on either side of the cap. The estimates turn out to be very robust to successively varying these values (Tab. 2 and 3).

Tab. 2: Discontinuity estimates - five year periods - sensitivity amount of bins

\begin{tabular}{|c|c|c|c|c|c|c|c|c|c|c|c|c|}
\hline \multirow[b]{2}{*}{ Period } & \multicolumn{4}{|c|}{$\begin{array}{c}\text { McCrary } \\
(2)\end{array}$} & \multicolumn{2}{|c|}{ (3) } & \multicolumn{6}{|c|}{$\begin{array}{c}\text { Polynomials } \\
\text { (2) }\end{array}$} \\
\hline & p.e. & $\mathrm{t}$ & p.e. & $\mathrm{t}$ & p.e. & $\mathrm{t}$ & p.e. & $\mathrm{t}$ & p.e. & $\mathrm{t}$ & p.e. & $\mathrm{t}$ \\
\hline 75-79 & .026 & 3.00 & .031 & 3.37 & .025 & 2.97 & .020 & 2.65 & .030 & 3.13 & .020 & 2.65 \\
\hline $80-84$ & .016 & 1.69 & .020 & 1.98 & .017 & 1.75 & .003 & .30 & .016 & 1.57 & .003 & .30 \\
\hline $85-89$ & -.006 & -.51 & -.005 & -.41 & -.006 & -.52 & .004 & .45 & -.014 & -1.39 & .004 & .45 \\
\hline $90-94$ & -.015 & -1.45 & -.015 & -1.47 & -.012 & -1.26 & -.003 & -.34 & -.009 & -.84 & -.005 & -.57 \\
\hline 95-99 & .008 & .73 & .007 & .64 & .008 & .70 & .000 & .00 & .008 & .80 & .001 & .10 \\
\hline 00-04 & -.001 & -.09 & -.001 & -.07 & -.002 & -.13 & .006 & .58 & -.003 & -.26 & .006 & .58 \\
\hline 05-10 & -.012 & -1.23 & -.015 & -1.43 & -.011 & -1.16 & -.014 & -1.46 & -.014 & -1.35 & -.007 & -.94 \\
\hline
\end{tabular}

Notes: $\Delta t$ - average drop in marginal SSC rate, p.e. - point estimate, $\mathrm{t}-\mathrm{t}$-value, $\mathrm{N}-$ observation in 1000s $(\alpha=0.05)$. Columns labeled (1) pertain to the basic specification with 200 bins on each side of the cap, for (2) the amount of bins is reduced to 150 , for (3) increased to 250 .

Source: SIAB; own calculations. 
Tab. 3: Discontinuity estimates - five year periods - sensitivity amount of observations

\begin{tabular}{|c|c|c|c|c|c|c|c|c|c|c|c|c|}
\hline \multirow[b]{3}{*}{ Period } & \multicolumn{6}{|c|}{ McCrary } & \multicolumn{6}{|c|}{ Polynomials } \\
\hline & \multicolumn{2}{|c|}{ (1) } & \multicolumn{2}{|c|}{ (2) } & \multicolumn{2}{|c|}{ (3) } & \multicolumn{2}{|c|}{ (1) } & \multicolumn{2}{|c|}{ (2) } & \multicolumn{2}{|c|}{ (3) } \\
\hline & p.e. & $\mathrm{t}$ & p.e. & $\mathrm{t}$ & p.e. & $\mathrm{t}$ & p.e. & $\mathrm{t}$ & p.e. & $\mathrm{t}$ & p.e. & $\mathrm{t}$ \\
\hline 75-79 & .026 & 3.00 & .031 & 3.31 & .026 & 3.00 & .020 & 2.65 & .03 & 3.13 & .02 & 2.65 \\
\hline $80-84$ & .016 & 1.69 & .019 & 1.89 & .016 & 1.69 & .003 & .30 & .022 & 2.20 & .003 & .30 \\
\hline $85-89$ & -.006 & -.51 & -.005 & -.50 & -.006 & -.51 & .004 & .45 & -.015 & -1.28 & .004 & .45 \\
\hline $90-94$ & -.015 & -1.45 & -.014 & -1.39 & -.011 & -1.16 & -.003 & -.34 & -.007 & -.60 & -.005 & -.57 \\
\hline 95-99 & .008 & .73 & .007 & .59 & .008 & .73 & .000 & .00 & .002 & .17 & .00 & .00 \\
\hline 00-04 & -.001 & -.09 & -.001 & -.07 & -.001 & -.09 & .006 & .58 & -.004 & -.33 & .006 & .58 \\
\hline $05-10$ & -.012 & -1.23 & -.014 & -1.42 & -.012 & -1.27 & -.014 & -1.46 & -.01 & -1.15 & -.01 & -1.16 \\
\hline
\end{tabular}

Notes: $\Delta t$ - average drop in marginal SSC rate, p.e. - point estimate, $\mathrm{t}-\mathrm{t}$-value,

$\mathrm{N}$ - observation in 1000s $(\alpha=0.05)$. Columns labeled (1) pertain to the basic specification with 400 observations per year in the first bin to the left of the cap. For (2) the amount of observations is reduced to 300 , for (3) increased to 500 .

Source: SIAB; own calculations.

In an additional sensitivity test we check whether zero (or very small) discontinuity estimates can also be found for East Germany. As shown above CBA coverage is substantially lower here (Fig. 2 above). The problem is that data for East Germany can be used effectively only between 1995 and 2000 (section 3 above). In the aftermath of the German unification wages and SSC institutions like earnings caps were adjusted rapidly. After 2001 the sample size gets small because the health insurance cap is high up in the earnings distribution (around the 90th quantile) and located close to the censoring threshold defined by the pension cap. For the pooled sample 1995-2000 we find discontinuities close to zero with both estimation approaches (results not shown). The conclusion of equal burden sharing thus also holds for East Germany.

Finally, an alternative explanation for our finding of mostly insignificant discontinuities would be a general identification problem. Analyzing discontinuities in net earnings can help to rule out this measurement issue. Alvaredo et al. (2016) show that due to their deterministic relationship either the distribution of gross or net earnings has to be discontinuous. If both are found to be smooth, the estimation approach lacks statistical power. Since we do not observe net earnings in the SIAB, we have to calculate them from gross earnings (Müller and Neumann, 2016). Given that those are mostly smooth, negative discontinuities in calculated net earnings arise deterministically. We are indeed able to identify these in different cross-sections with both estimation approaches (results not shown). As mentioned 
contribution rates have been raised over time (Fig. 1 above). This should increase discontinuities in net earnings for given incidence. We were also able to identify this longitudinal pattern in the estimates based on calculated net earnings.

\section{Conclusions}

In this study we analyze economic incidence of social security contributions (SSC) in West Germany over a time horizon of 35 years. The administrative SIAB data which contains precise individual gross earnings information from 1975 to 2010 for West Germany is utilized. We use the cross-sectional framework proposed by Alvaredo et al. (2016) that does not rely on (infrequent) reforms of SSC institutions or panel data. As argued the application of the discontinuity approach to high-quality earnings data in the SIAB allows for a consistent discontinuity analysis based on cross-sectional sub-samples over the whole observation period. We can therefore study how economic incidence has evolved over time.

According to our results statutory and economic incidence coincide. Neither employees nor employers shift a significant part of their SSC burden to the other side of the market. These results are very stable over the whole period observed between 1975 and 2010, robust to specification checks, and also consistent with estimates for East Germany. This provides a comprehensive body of evidence confirming recent findings for other countries (see the papers in this issue, Saez et al., 2012) and Germany (Müller and Neumann, 2016; Neumann, 2015).

There is a slight trend towards economic incidence of SSC falling more on the side of employees. This development would be consistent with previous findings and the decline in CBA coverage in Germany. However, given the small magnitude of differences over time and the statistical uncertainty attached to them we conclude that statutory equals economic incidence virtually for the full 35 years of data we observe. An actual causal analysis of the mechanisms driving this outcome remains for future research. 


\section{References}

Alesina, Alberto and Roberto Perotti, "The Welfare State and Competitiveness," The American Economic Review, December 1997, 87 (5), 921-939.

Alvaredo, Facundo, Antoine Bozio, Barra Roantree, and Emmanuel Saez, "Using threshold to estimate earnings responses to Social Security Contributions," Technical Report 2016.

Daveri, Francesco and Guido Tabellini, "Unemployment, growth and taxation in industrial countries," Economic Policy, April 2000, 15 (30), 47-104.

Dorner, Matthias, Marion König, and Stefan Seth, "Stichprobe der Integrierten Arbeitsmarktbiografien. Regionalfile 1975-2008 (SIAB-R 7508)," Documentation on Labour Market Data, Institute for Employment Research (IAB), Nuremberg 2011.

Fischer, Gabriele, Florian Janik, Dana Müller, and Alexandra Schmucker, "The IAB Establishment Panel - from Sample to Survey to Projection," FDZ Methodenreport. Methodological aspects of labour market data 200801EN, Institut für Arbeitsmarkt- und Berufsforschung (IAB), Nürnberg [Institute for Employment Research, Nuremberg, Germany] 2008.

_ , _ , , and _ , "The IAB Establishment Panel - things users should know," Schmollers Jahrbuch. Journal of Contextual Economics, 2009, 129 (1), 133-148.

Fitzenberger, Bernd, Karsten Kohn, and Alexander C. Lembcke, "Union Density and Varieties of Coverage: The Anatomy of Union Wage Effects in Germany," Industrial and Labor Relations Review, January 2013, 66 (1), 169-197.

Grabka, Markus, "Alternative Finanzierungsmodelle einer sozialen Krankenversicherung in Deutschland - Methodische Grundlagen und exemplarische Durchführung einer Mikrosimulationsstudie.," Dissertation, Technical University Berlin, 2004.

McCrary, Justin, "Manipulation of the running variable in the regression discontinuity design: A density test," Journal of Econometrics, 2008, 142 (2), 698 714 . 
Melguizo, Angel and Jose Gonzalez-Paramo, "Who bears labour taxes and social contributions? A meta-analysis approach," SERIEs, 2013, 4 (3), 247-271.

Müller, Kai-Uwe and Michael Neumann, "The Economic Incidence of Social Security Contributions - A Discontinuity Approach with linked EmployerEmployee Data," DIW Discussion Papers 1578, DIW Berlin 2016.

Neumann, Michael, "Earnings Responses to Social Security Contributions: Evidence from two German Administrative Data Sets," Technical Report, DIW Discussion Paper No. 1489, German Institute for Economic Research (DIW Berlin) 2015 .

OECD, "OECD revenue statistics," 2016.

https://stats.oecd.org/Index.aspx?DataSetCode=REV; accessed 2015.

Saez, Emmanuel, Manos Matsaganis, and Panos Tsakloglou, "Earnings Determination and Taxes: Evidence From a Cohort-Based Payroll Tax Reform in Greece," The Quarterly Journal of Economics, 2012, 127 (1), 493-533.

vom Berge, Philipp, Anja Burghardt, and Simon Trenkle, "Sample of integrated labour market biographies: regional file 1975-2010 (SIAB-R 7510)," FDZ Datenreport. Documentation on Labour Market Data 201309EN, Institut für Arbeitsmarkt- und Berufsforschung (IAB), Nürnberg [Institute for Employment Research, Nuremberg, Germany] April 2013.

_, Marion König, and Stefan Seth, "Sample of Integrated Labour Market Biographies (SIAB) 1975-2010," FDZ Datenreport. Documentation on Labour Market Data 201301EN, Institut für Arbeitsmarkt- und Berufsforschung (IAB), Nürnberg [Institute for Employment Research, Nuremberg, Germany] May 2013. 